\title{
Un martyrologe manuscrit : Marter-, Buss- und Tugend-Spiegel
}

\section{Daniel Bornemann}

\section{(2) OpenEdition \\ 1 Journals}

Édition électronique

URL : http://journals.openedition.org/rbnu/1561

DOI : 10.4000/rbnu. 1561

ISSN : 2679-6104

Éditeur

Bibliothèque nationale et universitaire de Strasbourg

\section{Édition imprimée}

Date de publication : 1 mai 2016

Pagination : 99

ISBN : 9782859230623

ISSN : 2109-2761

\section{Référence électronique}

Daniel Bornemann, « Un martyrologe manuscrit : Marter-, Buss- und Tugend-Spiegel », La Revue de la BNU [En ligne], 13 | 2016, mis en ligne le 01 mars 2020, consulté le 11 décembre 2020. URL : http:// journals.openedition.org/rbnu/1561; DOI : https://doi.org/10.4000/rbnu.1561

\section{(c) (i) (8)}

La Revue de la BNU est mise à disposition selon les termes de la Licence Creative Commons Attribution - Pas d'Utilisation Commerciale - Partage dans les Mêmes Conditions 4.0 International. 


\title{
NOUVELLES ACQUISITIONS PATRIMONIALES
}

\author{
Un martyrologe manuscrit : \\ Marter-, Buss- und Tugend-Spiegel
}

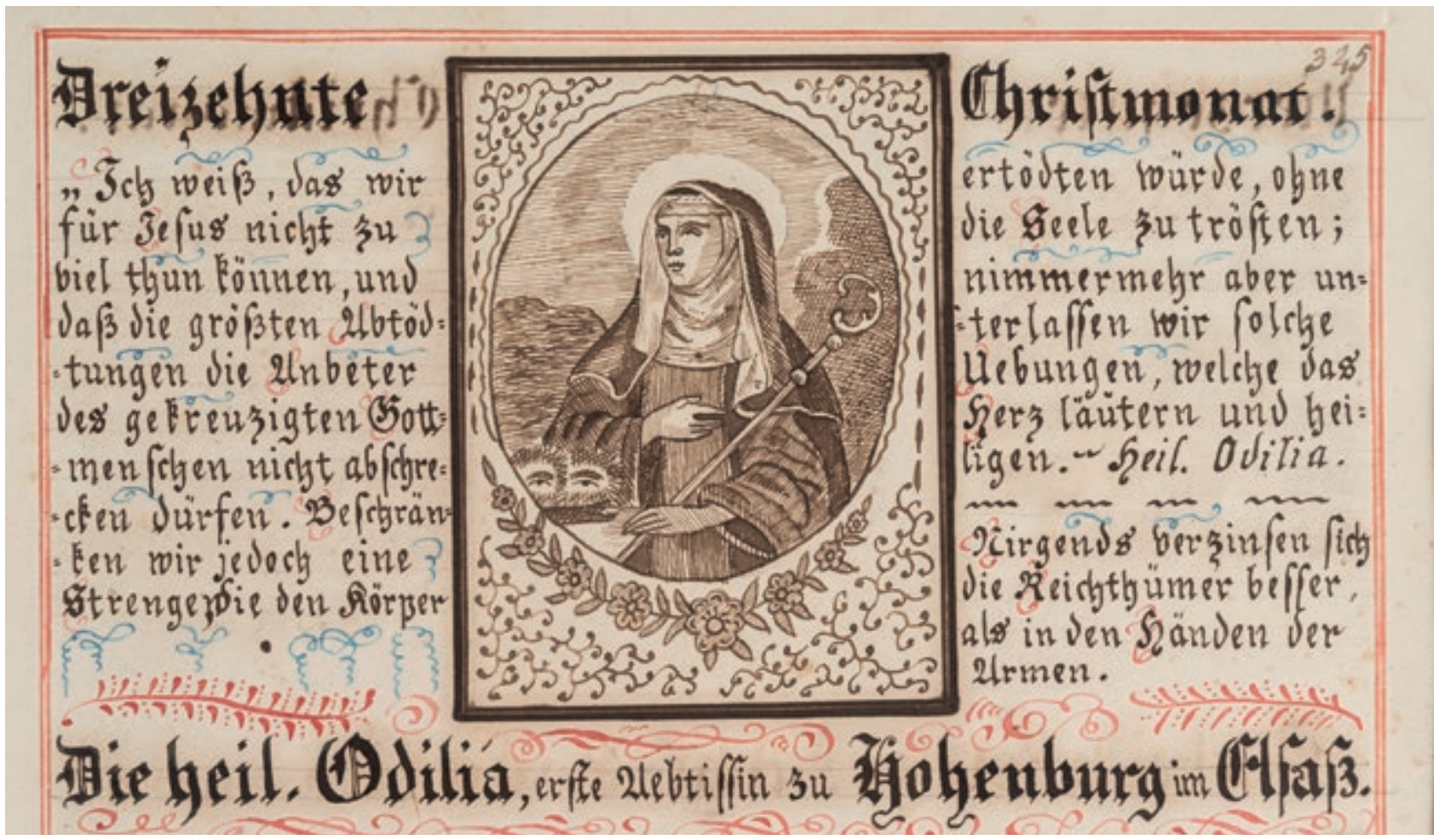

Impressionnant et inhabituel dans nos collections, le Miroir des martyrs, de la pénitence et de la vertu, tel qu'on pourrait en traduire le titre, est un témoin de la culture populaire catholique du Sud de l'Alsace. Son auteur, Gregorius Schmitt, inconnu par ailleurs, y a travaillé quatre années durant, de 1852 à 1855 , pour y dessiner et recopier, d'une écriture cursive allemande, les textes et les "portraits " de 368 saints et saintes. C'est donc ici un martyrologe (" calendarium sanctorum ") qui suit l'année liturgique définie par le concile de Trente. Les textes et même le titre complet sont directement inspirés d'œuvres éditées et répandues par les jésuites, plus précisément par les membres de la congrégation des marianistes. L'origine de l'ouvrage est à situer en Alsace méridionale. En attestent la présence de trois des cinq saints propres à la liturgie alsacienne (Arbogast de Strasbourg le 21 juillet, Florent de Strasbourg le 7 novembre et Odile de Hohenbourg le 13 juillet), mais aussi celle de saints propres à la Suisse. Rappelons que le sud de l'Alsace était rattaché à l'évêché de Bâle (établi à Soleure) jusqu'en 1802.

Le soin et la précision de la mise en page sont remarquables, avec par exemple une adaptation des interlignages à la longueur des textes,

afin d'offrir une uniformité de présentation aux pages. Les portraits sont expressifs quoique stéréotypés, et montrent une belle maîtrise des tracés et des proportions, même s'ils ont tous une sorte de raideur typique du milieu du $19^{\text {e }}$ siècle. Le décor luimême est constitué par les encadrements des portraits, presque tous différents les uns des autres, certains dans le goût néogothique. Autour des portraits figurent la date et des devises diverses, ornées de fioritures et de treillis à l'encre rouge et bleue.

\section{Daniel Bornemann}

